\title{
E. Meinlschmidt
}

\section{Gebietsfremde potenziell invasive Ackerunkräuter in Sachsen}

Online veröffentlicht: 25 August 2004

(C) Springer-Verlag 2004

\section{Gesunde Pflanzen (2004) 56:86-92}

Im oben genannten Beitrag kamen sowohl in der gedruckten als auch der pdf-Version auf den Seiten 91 und 92 Textpassagen durcheinander. Betroffen waren die Abschnitte über Topinambur und Riesen-Bärenklau. Die beiden Absätze lauten korrekt wie folgt:

Über das Auftreten von Topinambur (Helianthus tuberosus L.) in Weizen und Zuckerrüben wurde 2002 berichtet. Topinambur ist eine alte nordamerikanische Kulturart, deren Knollen essbar sind und auch als Viehfutter Verwendung finden. Dieses Korbblütlergewächs wird in Sachsen örtlich angebaut. Wenn diese Pflanzenart als Durchwuchs in nachgebauten Kulturen vorkommt, wie es in Ostsachsen der Fall war, ist sie schwer wieder auszurotten, da kleinste Knollen neue Pflanzen bilden. Dazu kommt, dass Topinambur bereits im Jugendstadium extrem konkurrenzfähig ist. Geeignete Kulturen für den Löschfruchtanbau sind Sommergetreidearten, da sie den Durchwuchs ausreichend unterdrücken können.
Die elektronische Version des Originalbeitrags ist verfügbar unter http://dx.doi.org/10.1007/s10343-0004-24-0

Dr. E. Meinlschmidt (

Fachbereich Pflanzliche Erzeugung, Referat Pflanzenschutz,

Sächsische Landesanstalt für Landwirtschaft,

Stübelallee 2, 01307 Dresden

E-Mail: Ewa.Meinlschmidt@fb4d.lfl.smul.sachsen.de

Tel.: +49-351-44083-17

Fax: +49-351-440 83-25
Der Riesen-Bärenklau gehört zu den aggressivsten invasiven Pflanzenarten Sachsens. Die Ausbreitung dieser aus dem Kaukasus eingeführten Pflanzenart erfolgt vorwiegend außerhalb von landwirtschaftlich oder gärtnerisch genutzten Flächen. In Einzelfällen sind Naturschutzflächen bedroht. Örtlich besiedelt er auch Wiesen und Weiden mit hoher Abundanz und versucht auf Ackerland vorzudringen (Abb. 8). In unseren Versuchen brachten die Behandlungen von Heracleum mantegazzianum mit Triclopyr (Garlon 4) sehr gute Bekämpfungserfolge von ca. $95 \%$. Die arbeitsintensiven mechanischen Maßnahmen, z. B. 6-mal Mähen innerhalb einer Vegetationsperiode, erreichten Wirkungsgrade von nur ca. $70 \%$. Bei kleinflächigen Beständen ist ein Abstechen und Ausgraben der Pflanze im April oder Ende Oktober zu empfehlen.

In der elektronischen HTML Version des Beitrags sind die beiden Absätze korrekt wiedergegeben. 